\title{
HOT BLAST STOVE CAMPAIGN EXTENSION REPAIRS AT OPERATING TEMPERATURE *
}

\author{
Edo Engel ${ }^{1}$ \\ Johan Barel ${ }^{2}$ \\ Rob Van Der Veek ${ }^{3}$ \\ Jan Bloem ${ }^{4}$
}

\begin{abstract}
Hot Blast Stove Technology has been developed to such an extent that low cost hot metal production for over 30 years without major repairs has become achievable, making the decision for a campaign length between 5 to over 30 years a design choice for the plant owner/operator. Some of the earlier examples of designs capable of such long campaign lengths are currently close to the $50^{\text {th }}$ year of their running campaign. These examples are found especially in Europe and North America. Along the duration of these campaigns, repairs to subsystems such as burners, hot blast outlets etc. may be required. Depending on a plant's up and down stream production capacities, the repairs may have to take place in the shortest possible time frame to minimize production loss. This article discusses an approach for intermediate repairs, executed while keeping the majority of the system at operating temperature.
\end{abstract}

Keywords: Hot Blast System, Hot Blast Stove, Campaign Extension, Hot Repair.

\footnotetext{
Manager Marketing, Danieli Corus BV, IJmuiden, The Netherlands.

M.Sc. and Senior Process Engineer, Danieli Corus BV, IJmuiden, The Netherlands.

Senior Designer, Danieli Corus BV, IJmuiden, The Netherlands.

Project Manager, Danieli Corus BV, IJmuiden, The Netherlands.
} 


\section{INTRODUCTION}

Whereas the campaign life capability of various hot blast stove designs may vary relatively widely, the actual success of an actual, individual hot blast stove or hot blast system of any design also depends largely on the quality of the applied materials and the quality and accuracy of installation. During the campaign, some parts of the system require more frequent repairs than others, the most prominent example of which is traditionally the hot blast stove burner. Other examples are the hot blast outlet, the connection between partition wall and ring wall, parts of the dome construction, etc. The causes for the repair requirement may be inherent to the design or e.g. related to operational aspects.

Whenever such a repair is required, the duration of the repair may be a major factor for consideration. If a plant's final products are in high demand or if the other blast furnaces cannot accommodate the related production loss (e.g. if the number of operating furnaces at the plant is small), achieving the shortest possible project duration becomes a priority. A major factor in a repair project's duration are the cooldown and heat-up periods required for Silica refractories. Given their non-linear expansion behaviour, these refractories should be cooled down and heated up with extreme caution within a specific temperature bandwidth and the time required for this exercise is as long as two weeks. For this reason, the ability to repair parts of the Hot Blast System while maintaining other parts of the system at operating temperature is one of the most attractive options for saving valuable time.

\section{Approach to Hot Repairs - Foldable Heat Shield}

Danieli Corus has developed an approach for the repair of hot blast systems that allows for the majority of the system's refractories to remain at operating temperature. The approach is based on the rapid installation of heat shields near the battery limits of the repair and the application of temperature monitoring systems in combination with additional burners to keep the system above a temperature of e.g. $800^{\circ} \mathrm{C}$. The heat shield design developed for this repair method was first applied during a hot blast system repair project at the Duisburg-Huckingen plant operated by Hüttenwerke Krupp Mannesmann GmbH (HKM).

This project entailed repairs of the burners of all of the three external combustion chamber design hot blast stoves, as well as the replacement of the hot blast main end cover and a variety of repairs on other parts of the system. For the burner repairs and the local repairs at the hot blast outlets, a foldable heat shield was installed inside the burner shaft, directly above the hot blast outlet. The refractories in the burner shaft and checker chamber were kept at a minimum temperature level by means of natural gas burners. After sufficient cool-down of the area below the heat shield, the burners could be repaired. 


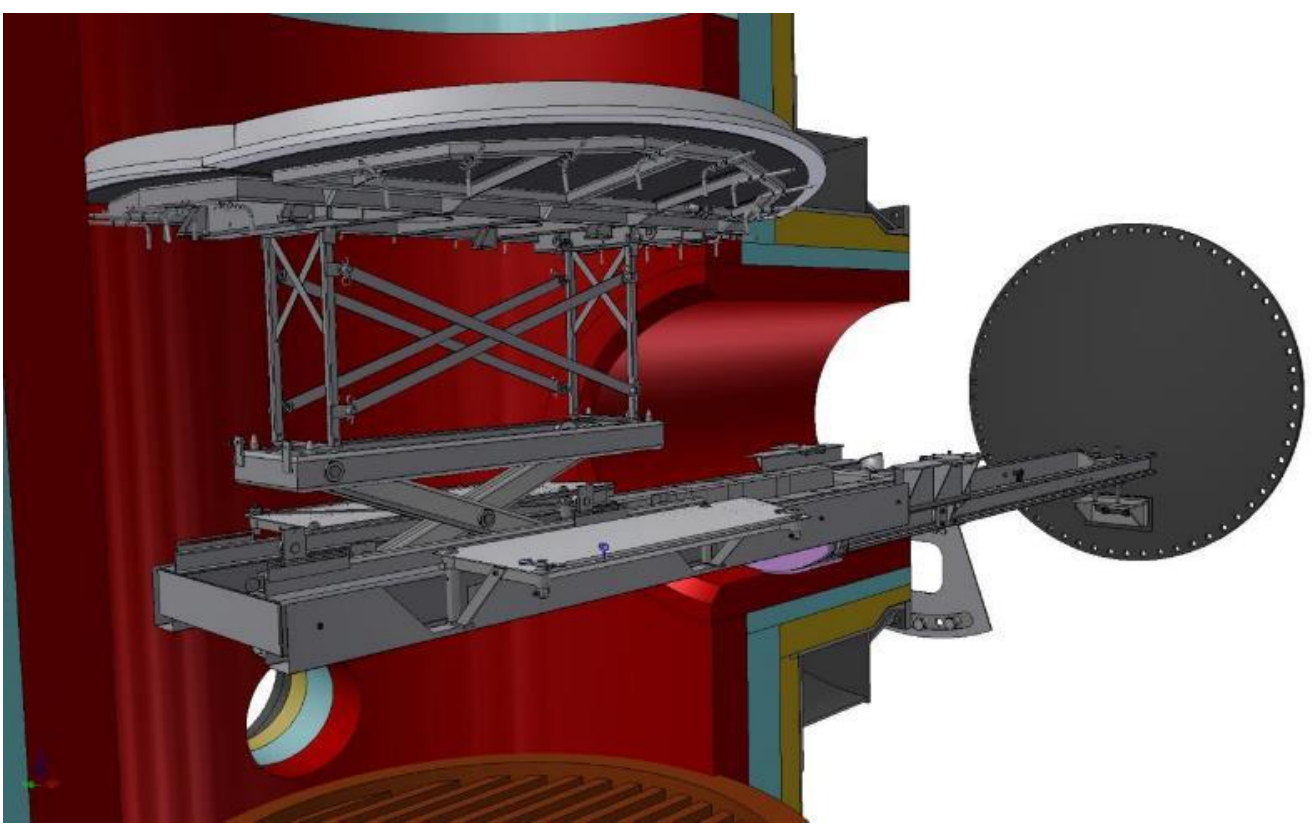

Fig. 1 - Heat Shield Design

The heat shield is modular in design and consists of a Carriage Rail Support, Main Carriage, Heat Shield Extendable Support, Foldable Heat Shield, Drive Extension Frame, Temporary Support Frame and an additional Heat Shield Support Frame.

Before the installation of the heat shield, the hot blast stove is depressurized and the hot blast valve and the hot blast stove expansion joint removed. An insulating heat plug is installed within the hot blast outlet at the burner shaft end, allowing for the installation of the heat shield under ambient conditions.

The carriage and its rail support are hoisted into position using an overhead crane, with the carriage rail support getting attached to the hot blast outlet flange and (in the HKM project) the T-junction of the hot blast main. The foldable heat shield and its extendable support are installed on the main carriage and pushed forward to just before the heat plug. Hoses for compressed air (for the cooling of the heat shield itself) and ambient air (fan-blown, for the cooling of the frames and carriage) are connected. The drive extension frame, with its winches, gearboxes and extension rods for the folding and unfolding operation of the heat shield, is attached. Finally, the foldable heat shield is pushed beyond the heat plug into the burner shaft with the heat plug being pushed out by it. The heat shield is unfolded remotely and lifted to a position just above the hot blast outlet opening to allow for cool-down.

After the area below the heat shield is cooled down sufficiently to create safe working conditions, additional support frames are installed from below and side platforms are attached to the carriage. The burners and temperature monitoring system are installed through the heat shield. 


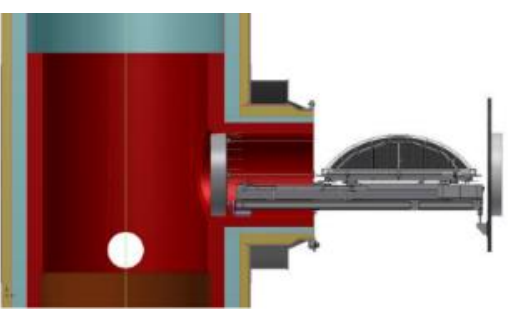

Fig. 2 - Carriage and heat shield hoisted in

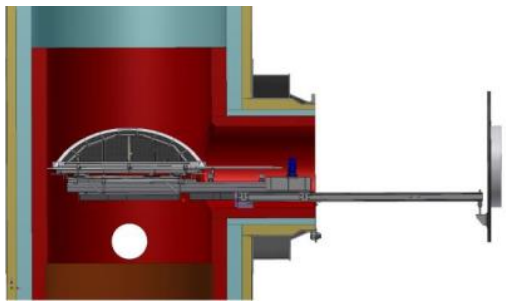

Fig. 3 - Heat shield pushed through heat plug

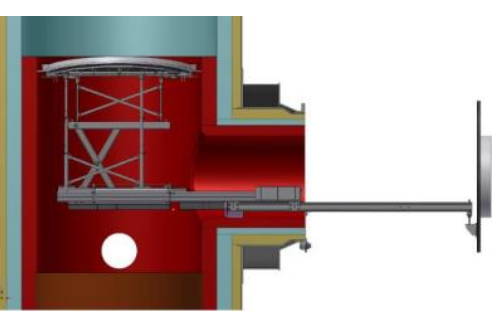

Fig. 4 - Heat shield in final position

All of the modules are fabricated using AISI 310S stainless steel for high strength at elevated temperatures. The compressed air hoses are sheathed in heat resistant material. The first layer of insulation of the foldable heat shield consists of high temperature, micro-porous ceramic board capable of withstanding temperatures in excess of $1200^{\circ} \mathrm{C}$. On top, another insulating layer of ceramic fibre-based felt and blanket enveloped in high temperature cloth is installed. Around the heat shield, a sealing ring made out of heat resistant blanket and heat resistant sleeve material is placed between the outer edge of the heat shield and the hot blast stove refractory wall.

Some of the equipment and sub-assemblies are protected against heat by additional, local heat shields. The drive extension frame, with its gearbox oil and lubricants that may burn when exposed to excess heat, is such an example. The heat shield folding and unfolding operation is executed remotely by means of drive rods and gearboxes, but in case of failure of the remote folding at the end of the repair period, a fall-back system based on pull chains and chain wheels is available. The sequence of removing the foldable heat shield after completion of the repair is largely the reverse of the installation sequence.

\section{Case Study - Hot Blast System Repair at HKM Blast Furnace B}

Blast Furnace $B$ at the Duisburg-Huckingen plant owned and operated by HKM was first commissioned in 1981. Its last major reline took place in 2000. It is a $2824 \mathrm{~m}^{3}$ working volume furnace that produces 2.7 million tonnes of hot metal per annum. The hot blast system consists of three stoves of an external combustion chamber design built in 1994. The hot blast main is positioned at a higher elevation than the bustle pipe and oriented at an offset from the blast furnace center line. Both this vertical and horizontal offset are accommodated in the system's mixing pot, which also has a cold blast inlet for hot blast temperature control. Since the hot blast main is lined with Silica, it was also kept at operating temperature. 


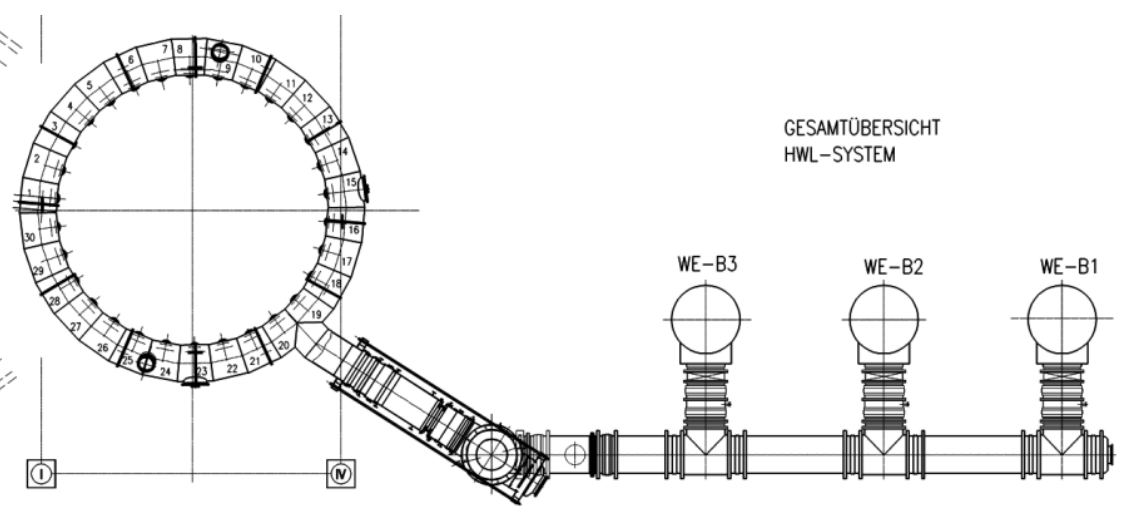

Fig. 5 - HKM Blast Furnace B Hot Blast System (note: checker chambers omitted)

HKM contracted Danieli Corus for the repair of the hot blast stove burners, repairs to refractories of and around the hot blast outlets, the replacement of the hot blast main end cover, and some additional work such as the replacement of the back draft stacks. The repair project was to be executed in parallel with a furnace reline and the modernization of the gas cleaning system. Given the critical time path and since Blast Furnace B produces more than half of the plant's hot metal, furnace downtime was to be minimized and it was decided to eliminate the heating up and cooling down of the hot blast stoves as much as possible by executing the repairs while keeping the majority of the system at operating temperature.

At the start of the project, an inspection of the hot blast main and bustle pipe was executed to establish the scope of all the required repairs (some of which outside of the scope to be executed by Danieli Corus). Following this inspection, HKM decided to cool down the bustle main and the part of the hot blast main downstream of the mixing pot for repairs, while keeping the mixing pot and the upstream portion of the hot blast main at operating temperature. Under these conditions, the hot blast main and mixing pot end covers including thrust collars were replaced and the refractory lining of the mixing pot hood replaced.

The stove burners were repaired one by one. The other two stoves were kept hot with main burner with blast furnace gas supplied by Blast Furnace $A$. The hot blast main was kept hot by blowing back through the stove(s) to the mixing pot valve and a temporary chimney installed on the mixing pot outlet. In preparation of the actual repair jobs, the heat shield assemblies were submitted to repeated tests, the final one of which took place in a mock-up situation erected at the HKM site. 


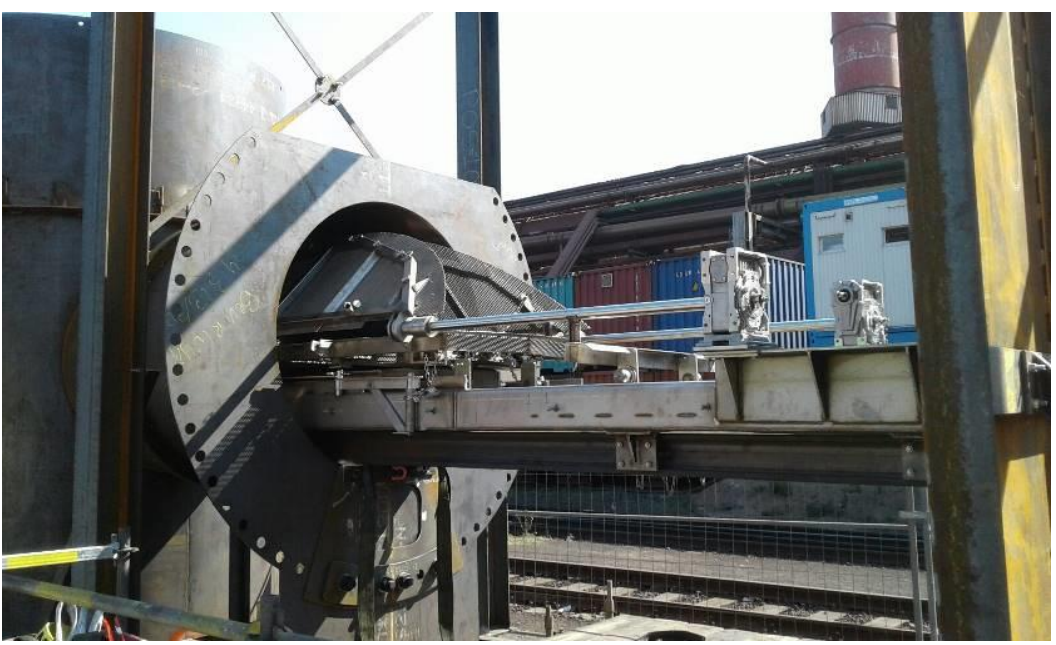

Fig. 6 - Trial set-up at HKM site
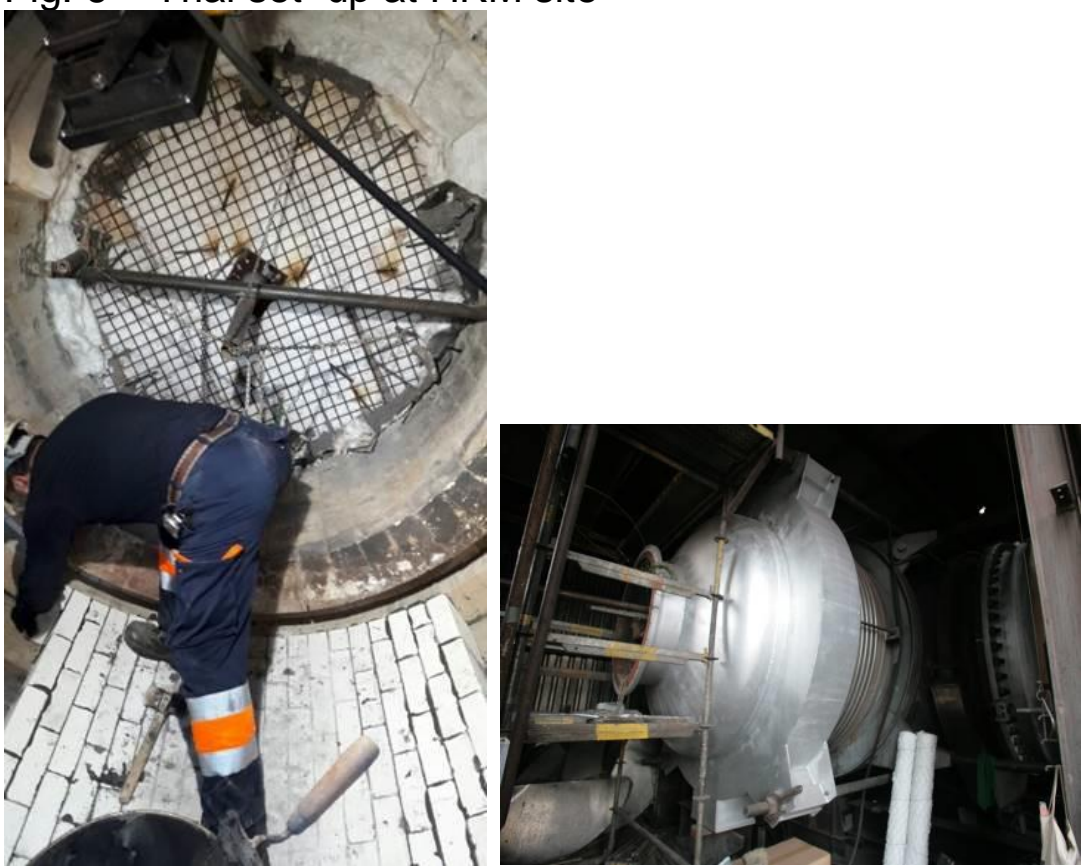

Fig. 7 - Hot blast main end cover during repair vs. end result

The burner repairs entailed the replacement of the top seven layers. The repairs took two to three weeks each from the moment of isolation until reconnection. For the repair of each of the hot blast stove burners, a dedicated folding heat shield with insulation panels/blanket was available. Two sets of the sliding/supporting assemblies were expedited to the HKM site, one for repeated use and a spare unit. The installation, insertion, lifting and unfolding operation in the harsh environment around the (plugged) hot blast outlet and (plugged) hot blast main T-junction did not introduce any complications. After insertion of the heat shield during the repair of the third burner, the unfolding mechanism jammed owing to a misguided back-up chain. The heat shield was retracted and another unit reinserted after a new set insulating panels/blankets was installed without causing any prohibitive delays. 

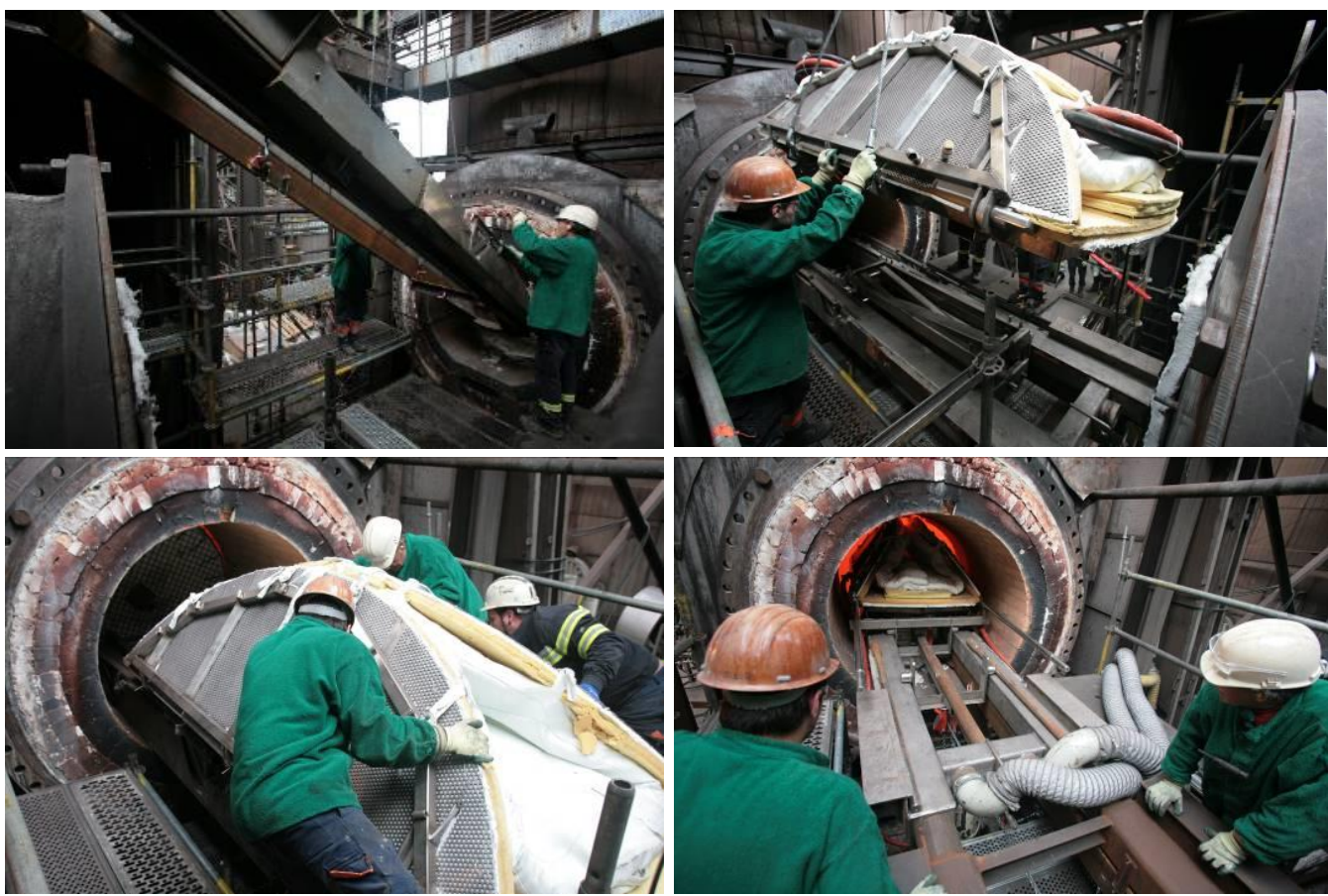

Fig. 8 - Installation of the heat shield

The folding heat shields accommodate the insertion of two burners through the heat shield and into the area above it; for each of the three repairs, only one of these was utilized. A temperature monitoring system was also installed through the heat shield, allowing to maintain a temperature in the burner shaft above $800^{\circ} \mathrm{C}$ to prevent any detrimental expansion or contraction behaviour of the refractories.

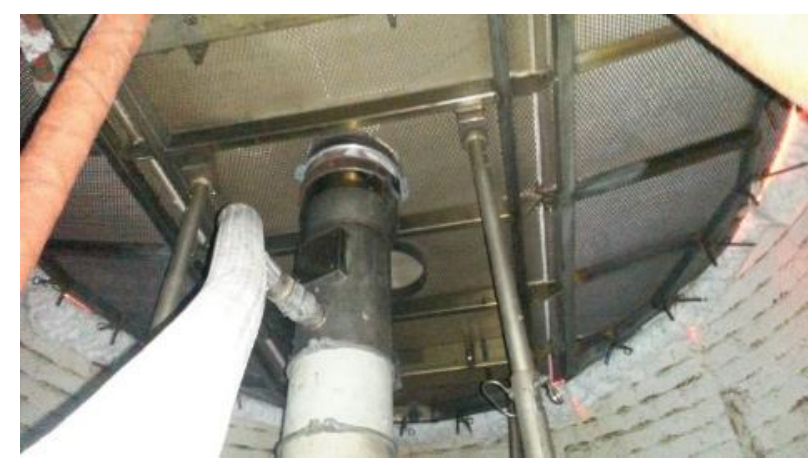

Fig. 9 - Burner in position

During the repair period of the ceramic burner, the natural gas burner was fired during the night and demolition/installation was executed during daytime. Below the heat shield, the working environment was cooled down with temporary fans connected to gas and air connection below the ceramic burner to workable temperatures in 24 hours. Demolition and refractory installation was executed in daytime and groups of staff, equipped with special PPE and clothing depending on temperature conditions, executed the work in an alternating manner. After completion of each of the burner repairs and removal of the heat shield, a natural gas burner was used to heat up the new ceramic burner. This natural gas burner was inserted through the pilot burner nozzle. 


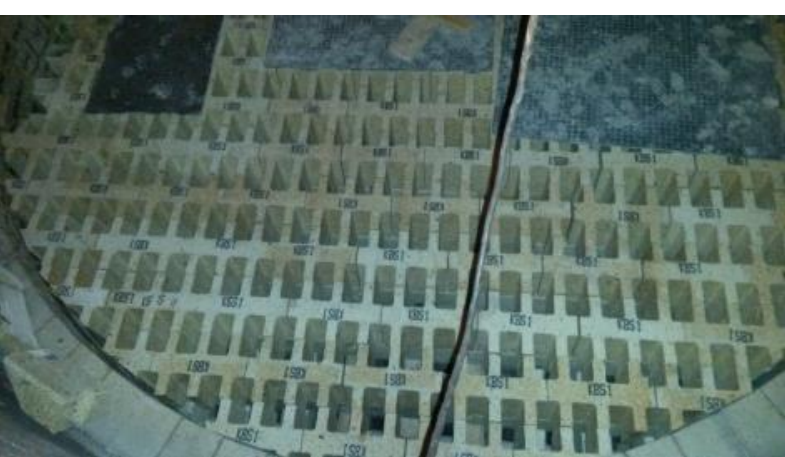

Fig. 10 - Burner after repair

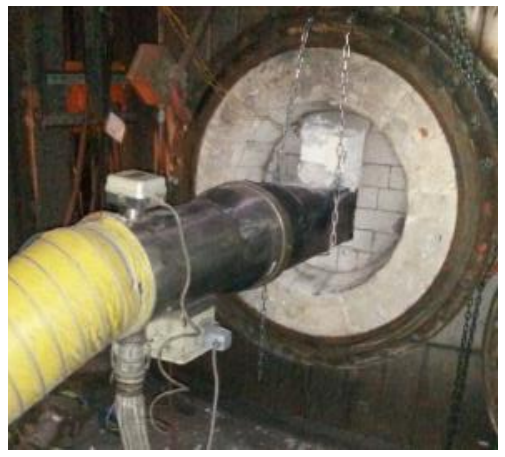

Fig. 11 - NG burner for re-heating

Refractory temperatures were monitored in $24 / 7$ shifts by Danieli Corus Process Engineers. The objective was to maintain a refractory temperature above $800^{\circ} \mathrm{C}$. Data for thermocouples already in place within the system was logged and additional thermocouples were installed in a number of locations. An example of the temperature curve of at one such a location is shown in the diagram in Figure 12, in this case the dome temperature of Hot Blast Stove No. 2 during the fourth week of the project. The green horizontal lines also indicate whether or not the corresponding burner was operating. (Thermocouple T3M2 is located in the checker chamber $1 \mathrm{~m}$ above the checker grid.)

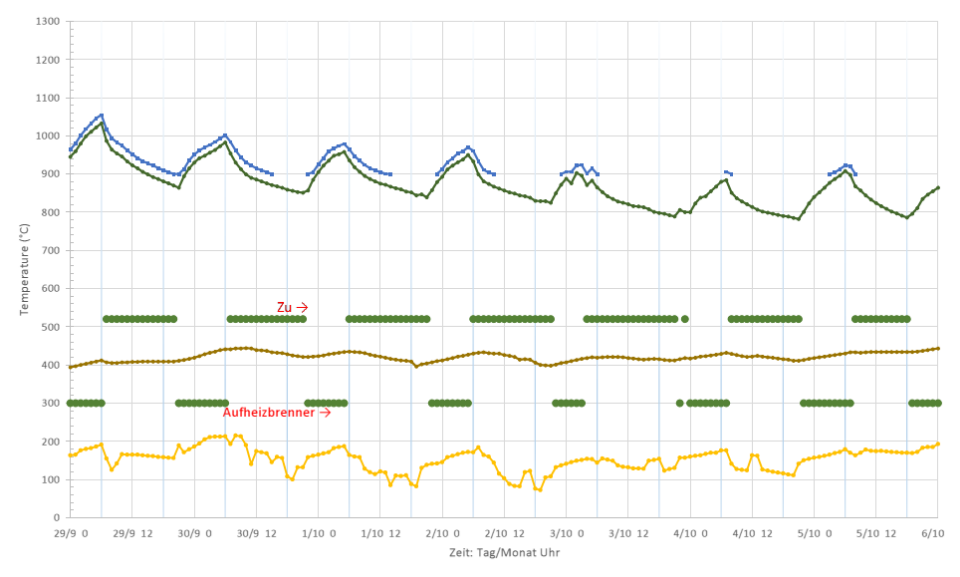

Fig. 12 - Temperature monitoring and management

Whereas the hot blast stove refractories (burner shaft, dome and checkerwork) were kept at their respective minimum temperature by means of the natural gas burner installed through the heat shield, the (silica-lined) hot blast main was reheated when necessary by utilizing heat from one the stoves, for which the repairs had been finished or not started. It was decided that a provisions for maintaining a maximum temperature at the checker grid had to be made. A small stack was installed on the stove dome to allow for cold air to be introduced from below the grid when necessary. In most cases, temperatures were kept above target level. There was a small number of occasions where the measured temperature dropped below the specified levels. Since the air temperature was measured and not the refractory temperature, this served as an early warning and through quick fact finding, root causes (such as a leaking valve) could be identified and measures taken. 
The repair jobs were completed within the pre-defined time frame for the project and without any lost time incidents. The system was recommissioned successfully and the furnace has resumed production.

\section{CONCLUSION}

Repairs to parts of hot blast systems can be executed successfully while maintaining the majority of the system at operating temperature through the application of heat shields to save substantial time;

Maintaining the desired temperature levels requires $24 / 7$ temperature monitoring and management;

Given the sliding, folding and shearing mechanisms of the foldable heat shield and its sub-assemblies, the utmost attention has to be given to health and safety during the design phase;

Under the operating conditions for such repairs, even equipment and materials engineered for these conditions may fail; having sufficient stock of spare parts and materials on site during the execution of the project is paramount. 